\title{
Resenha
}

O nome atual do mal-estar docente

Pereira, M. R.

Belo Horizonte, MG: Fino Traço, 2016, 244 p.

\section{O NOME ATUAL DO \\ MAL-ESTAR DOCENTE}

\author{
Telma Lima Cortizo
}

DOI: http//dx.doi.org/10.11606/issn.1981-1624.v22i1p185-191.

"Tudo está na palavra. Uma ideia inteira muda porque uma palavra mudou de

lugar ou porque outra se sentou como uma rainha dentro de uma frase que não a esperava e que a obedeceu. Têm sombra, transparência, peso, plumas, pelos, têm tudo o que, se lhes foi agregando de tanto vagar pelo rio, de tanto transmigrar de pátria, de

tanto ser raízes."

(Pablo Neruda, 1978, p. 51)

Os versos de Neruda remetem à força da palavra: significante fundante para a psicanálise e ferramenta que torna possível a operação do trabalho analítico (Millot, 2001). É por meio da palavra que o analista, demandado pelo paciente e investido no lugar de sujeito suposto saber, aplica a escuta à palavra franca, marcando o ato inaugural que precipita o advir do sujeito. Dessa fenda que se abre, sucedendo a variáveis de significantes, a palavra escapa e irrompe o silêncio; "subtende o desejo e a castração, pois outro corpo é necessário para assegurar o corte do qual o sujeito se desprende e se recobre" (Kaufmann, 1996, p. 189). No jogo de palavras disfarçadas, escamoteadas e dissimuladas nas repetições, nos silêncios e nas pausas, se precipitam rasgos de entrada que podem tornar acessíveis os escombros do inconsciente e reatualizar acontecimentos traumáticos

- Doutoranda do Programa de Pós-Graduação e pesquisadora do Grupo de

Estudos e Pesquisas em Psicanálise, Educação e Representações Sociais (Gepers) da Universidade do Estado da Bahia. Professora da Fundação Visconde de Cairu - Instituto de Ensino Superior, Salvador, BA, Brasil. 
que deram origem ao sintoma. Essa afirmação reitera a palavra como ferramenta essencial na experiência analítica.

Não é por acaso que o livro O nome atual do mal-estar docente, escrito pelo professor e psicanalista Marcelo Ricardo Pereira, trata do padecimento dos professores na contemporaneidade. $\mathrm{O}$ fio condutor que ancorou a construção conceitual da escrita foi a escuta da palavra, em instância coletivizada (espaço de fala) e em instância individual (entrevista de orientação clínica). Sendo a palavra docente estatuto de enunciado e anunciação, a publicação é uma costura teórica metodológica e empírica empreendida pelo autor com uma clareza argumentativa ímpar no sentido de desvelar nuances e singularidades que se escondem sob o véu desse dito por dizer e desse dizer não dito.

A obra faz parte de uma tetralogia que compreende os estudos de psicanálise, educação e formação de professores, a saber: $O$ avesso do modelo: bons professores e a psicanálise (2003); A impostura do mestre (2008) e Acabou a autoridade? Professor, subjetividade e sintoma (2011). As publicações seguem uma linha de investigação que aborda a psicanálise e a educação num par dissimétrico e sem hierarquia, permitindo elaborações sobre a subjetividade docente. Cada título apresenta uma questão de pesquisa específica, sendo visível, entretanto, um encadeamento discursivo amparado numa coerência textual que embasa e legitima a tetralogia. A obra, revestida de uma consistência teórica metodológica reflexiva, revela um compromisso ético com a pesquisa e com a psicanálise, refutando uma visão reducionista ou generalista. Ela se encontra dividida em três partes mais o posfácio.

A primeira parte é nomeada "Metanálise sobre o padecimento psíquico de professores", na qual são apresentados e debatidos os resultados de pesquisas realizadas no âmbito da América Latina, da América do Norte, da Europa e da Oceania que confirmam o padecimento docente. Subdivide-se em dois capítulos: "Padecem mais os que ensinam?" e "A saúde de professores brasileiros: estudos recentes". A análise dessas pesquisas põe em causa a tese de que os professores padecem mais de doenças da alma (psíquicas) do que a média de outros profissionais, colocando em suspeição essa ideia de que há mais professores adoecidos do que na maioria da população. Pereira (2016) afirma que tal evidência não exclui a hipótese de que alguns docentes manifestam modos singulares de sofrimento psíquico, sendo esse o seu objeto de investigação clínica. A segunda parte, intitulada "Docentes em estado depressivo", apresenta o resultado da pesquisa-intervenção e conta com quatro capítulos: "O que fizemos: questões de método"; "Vulnerabilidade do professor e quadros depressivos"; "As singularidades discursivas: caso a caso"; "O

186 Estilos clin., São Paulo, v. 22, n. 1, jan./abr. 2017, 185-191. 
que quer um docente que se diz em estado depressivo". A terceira parte, chamada "Adendos a Tetralogia", retoma livros anteriores para escrever os dois capítulos finais: "Pode autorizar-se de si mesmo o professor?" e "Os profissionais do impossível". O posfácio, denominado "A transitoriedade do mestre contra a sua impostura", é a transcrição de uma entrevista do autor, em 2010, realizada pela editora Fino Traço (à época Argvmentvm). A implicação com a psicanálise e com educação emerge no discurso objetivo e claro do autor, esclarecendo pontos relevantes sobre questões que atravessam o saber profissional, contextos e o lugar do professor na sociedade atual. Chama a atenção para a colonização de um suposto quadro generalizado de fobia da docência e admite que o desgaste no cotidiano da sala é manifesto de resistências diferenciadas, que pode implicar ou não em sofrimento psíquico.

Boa parte do texto desenvolvido, no que tange à parte empírica do estudo, procede dos achados da pesquisa-intervenção de uma equipe da Universidade Federal de Minas Gerais nomeada "Padecimento de professores como efeito dos excessos da juventude contemporânea". Participaram dos espaços de fala mais de cinquenta sujeitos de escolas públicas da cidade de Belo Horizonte, numa média de seis professores por escola, por meio de um mapeamento realizado na Secretaria de Educação sobre professores que se afastaram por licença médica. Destes, quinze foram escutados através de entrevistas de orientação clínica e de observação de regularidades. As ferramentas utilizadas foram: mapeamento; espaço de fala; entrevista de orientação clínica; observação de singularidade; diário de bordo; e diário clínico. O autor destaca como ferramenta crucial o espaço de fala, similar às conversações (Miller, 2005), porém mais aprofundada,

propiciamos o que se pode chamar associação livre coletivizada, uma variável tanto quanto polêmica - mas necessária - do princípio técnico basilar da psicanálise: a associação livre. ... Nosso intuito foi colocá-los continuamente em uma atitude de reflexão, de elaboração ou de subjetivação (Pereira, 2016, p. 91).

Para os encontros com os sujeitos, utilizou o que denominou princípio freudiano do jogo de xadrez, em que, contrapondo início e final - que podem ser previsíveis -, há uma variedade de jogadas a serem realizadas. O método utiliza três conceitos-chave da psicanálise: transferência; escuta flutuante; e a palavra franca. Sob a tríade elaborada por Freud - recordar, repetir e elaborar -, tendo 
como técnica a associação livre, a investigação foi orientada com vistas a instigar o docente a refletir sobre sua prática, a "formalizar seus impasses, para daí destravar identificações, construir saídas e elaborar-se" (Pereira, 2016, p. 77). Para além, seguindo a vertente clínico-reflexiva, enfatiza o âmbito social da psicanálise e não o terapêutico. Segundo o autor há uma demanda invertida, isto é, a pesquisa ocorre pelo desejo do pesquisador e não do sujeito, inverso ao que se dá na clínica. No entanto, isso não significa que o sujeito não possa se comprometer com a pesquisa - isso acontecerá pelas identificações e pela transferência. O pesquisador, mesmo sem ser psicanalista, pode desenvolver pesquisa de orientação clínica, salvaguardando os seguintes princípios éticos: ter feito análise e interrogado seus sintomas; aceitar a hipótese do inconsciente; e, pela transferência, exercitar o lugar de sujeito suposto saber (Pereira, 2016).

O livro apresenta bons argumentos sobre a importância de o pesquisador criar seu próprio caminho, sem cair na tentação da padronização, oferecendo princípios metodológicos relevantes para a pesquisa-intervenção e mostrando uma visão alargada da clínica - ou, mais precisamente, o que denomina atitude clínica. Para além da pesquisa-ação ou da pesquisa participativa, a pesquisa-intervenção de orientação clínica tem se apresentado como uma opção metodológica que rompe com as perspectivas tradicionais porque "trata-se de uma proposta de atuação transformadora da realidade subjetiva, já que propõe uma intervenção de ordem microfísica na experiência do sujeito no âmbito social" (Boaventura \& Pereira 2016, p. 59). Nessa rubrica, outra grande contribuição da pesquisa remete ao investimento nas singularidades discursivas (e não tanto nas regularidades), exploradas com pormenores no capítulo "As singularidades discursivas: caso a caso", etapa em que quinze professores aceitaram ser escutados individualmente, dizendo-se com sintomas psíquicos variados em razão da complexa experiência com os adolescentes. $\mathrm{O}$ autor declara que "cada docente foi tomado como caso único" (Pereira, 2016, p. 115), de modo que cada relato revela as elaborações e repetições que possibilitaram intervenções do pesquisador no intuito de faz̧er vacilar o sintoma. As histórias dos sujeitos tomam acentos e recortes próprios, por isso não suportam generalizações: cada caso fornece informações singulares sobre seus sintomas e sofrimentos.

Nessa linha de pensamento apresentada por Pereira (2016), o padecimento pode se constituir como ganho para o docente, uma arma disponibilizada contra esse outro social, cujas transformações, intensificadas nos últimos cinquenta anos e capturadas pelo recrudescer da lógica neoliberal - tecida, por sua vez, sob as malhas das tecnologias em expansão - marcam o advir

188 Estilos clin., São Paulo, v. 22, n. 1, jan./abr. 2017, 185-191. 
de novas formas de subjetivação do sujeito. Nesse cenário, pautado pela busca incessante de gozo, pelo narcisismo exacerbado e pela acentuada desregulação do consumo

a indiferença cresce ... o discurso do Mestre está banalizado, dessacralizado e o ensino é uma máquina neutralizada pela apatia escolar. ... E os docentes um corpo fatigado, incapaz de lhe devolver a vida (Lipovetsky, 2014, p. 67).

A modernidade líquida (Bauman, 2001), o fim das metanarrativas e o processo de dessimbolização do mundo (Dufour, 2005) acedem formas de organizações mais flexíveis, híbridas e autônomas, rompendo com tradições ou formas verticalizadas em que a repressão e a culpa parecem não ter mais espaço. Nessa visada, o sujeito contemporâneo é capturado pelo culto à imagem, pelos excessos, pelo Supereu ativado pelo gozar sem limites, em que o recuo da castração desenvolve sintomas diferenciados, "[...] desde a segunda teoria das pulsões em Freud, e com Lacan, que o sujeito prefere o gozo à autoconservação, e que o narcisismo não é barreira contra a pulsão de morte" (Laurent, 2007, p. 169). $\mathrm{Na}$ sociedade atual, o sujeito pode atentar a morte de várias maneiras, e cada uma é uma forma específica de sintoma. Na medicina, a identificação da sintomatologia aliada com a empresa farmacológica é o caminho irredutível para o processo de cura do sujeito. A psicanálise, por sua vez, anuncia que o sintoma psicanalítico se elabora no avesso do discurso científico, na medida em que aposta na palavra em detrimento do uso de medicamentos (Martinho, 2001). Assim, o sintoma é constituído de sentidos e seu estatuto inaugura a entrada do sujeito em análise, constituindo-se como linguagem, cujos não ditos têm um dizer sobre o sujeito.

Evoco as palavras de Rose Gurski, que magistralmente no prefácio afirma que

a escrita do livro nos dá o testemunho não somente da história de uma pesquisa, mas, sobretudo, evoca o caminho trilhado por um investigador cuja inquietação e honestidade intelectual são generosamente divididas com seus interlocutores (Gurski, 2016, p. 12).

E enfatizo que são muitos os motivos que instigam à leitura desse título. A sistematização pormenorizada dos passos da pesquisa-intervenção de orientação clínica e a análise das falas sobre o padecimento docente, a partir da pergunta "O que quer um docente que se diz em estado depressivo?" (Pereira, 2016, p. 147), parece convocar o leitor a desmontar os pedaços do quebra-cabeça do caso a caso, cuja escuta das singularidades daqueles que se propuseram a participar dessa etapa da investigação de forma mais estrita corrobora a compreensão do enigma que se esconde sob a égide do padecimento docente na sociedade atual, na qual o gozar a qualquer preço parece ser 
um imperativo (Laurent, 2007; Pereira, 2016). Nesse movimento, as hipóteses apresentadas anunciam que o ato de covardia moral, de ceder de seu desejo e da demissão subjetiva podem se constituir em mote de defesa do eu para o estado depressivo. O cair antes da queda, ou a fuga para a doença, é o sintoma utilizado como escudo na tentativa de dissimular lacunas conceituais, sociais e políticas. Ocorre que a escola não tem contribuído para minimizar esse estado de fadiga e torpor que parece acometer um grande número de professores que se ressentem e se dizem desautorizados. Pereira (2016) argumenta que a instituição escolar, quase sempre regulada por um processo de maternagem e burocratização, tem se alijado de ajudar o professor a recobrar sua coragem moral para lidar com as idiossincrasias do saber profissional. Dessa forma, o autor afirma, "paga-se caro e com seu próprio corpo quando o professor se fixa discursivamente e tende a se nomear através de seu sofrimento" (Pereira, 2016, p. 198). Faz-se necessário que o docente admita o impossível de educar para restituir a potência de seu ato. É assumindo sua condição de não todo, compreendendo o caráter circunstancial, contingente e provisório da mestria que poderá mostrar-se potente para o ato pedagógico. Todavia, as políticas de formação precisariam deixar de lado uma visão dicotomizada, padronizada e automatizada da racionalidade técnica para dar lugar a uma aproximação das micropolíticas e das experiências microfísicas. A escuta psicanalítica, ou atitude clínica, pode corroborar na medida em que oferta a palavra franca, no sentido amplo, permitindo que a palavra circule, impactando, destravando e desinstalando, para que dela possa emergir algo novo, na contramão da inércia do sintoma, permitindo novos modos de subjetivação de professores, revertendo o que o autor nomeia como o mais expressivo nome do mal-estar docente hoje: o estado depressivo. Portanto, a leitura desse livro nos convoca a pensar sobre perspectivas e saídas que endereçam ao saber-fazer com o sintoma. Quem sabe se, por essa via, tendo como aporte a atitude clínica de escutar a experiência dos professores que padecem ou não, seja possível vislumbrar as causas e o enfrentamento de suas angústias? Quiçá, aqueles depressivos e desencantados possam apreender uma nova potência para o exercício da docência sem desistir ou padecer. Nesse sentido, o livro presenteia o leitor com pistas preciosas. 


\section{Resenha}

\section{REFERÊNCIAS}

Bauman, Z. (2001). Modernidade líquida. Rio de Janeiro, RJ: Zahar.

Boaventura Jr., M., \& Pereira, M. R. (2016). Lá fora... na rua é diferente!: adolescência, escola e recusa. Curitiba, PR: Appris.

Dufour, D.-R. (2005). A arte de reduzir as cabeças: sobre a nova servidão na sociedade ultraliberal. Rio de Janeiro, RJ: Companhia de Freud.

Gurski, R. (2016). A maior riqueza da educação é sua incompletude: assim dizem os mestres. In M. R. Pereira, O nome atual do mal-estar docente (pp. 9-16). Belo Horizonte, MG: Fino Traço.

Kaufmann, P. (1996). Dicionário enciclopédico de psicanálise: o legado de Freud e Lacan. Rio de Janeiro, RJ: Jorge Zahar.

Laurent, É. (2007). A sociedade do sintoma: a psicanálise, hoje. Rio de Janeiro, RJ: Contracapa.

Lipovetsky, G. (2014). A era do vazio: ensaios sobre o individualismo contemporâneo. Lisboa: Ediçôes 70.

Martinho, J. (2001). Freud \& companhia. Porto: Almedina.

Miller, J. A. (2005). La pareja e el amor: conversaciones clinicas com Jacques AlainMiller em Barcelona. Buenos Aires: Paidós.

Millot, C. (2001). Freud antipedagogo (A. Roitman, trad.). Rio de Janeiro, RJ: Jorge Zahar.

Neruda, P. (1978). Confesso que vivi: memórias (O. Savary, trad.). Rio de Janeiro, RJ: Difel.

Pereira, M. R. (2016). O nome atual do mal-estar docente. Belo Horizonte, MG: Fino Traço.

telmalcortizo@uol.com.br

Rua Silveira Martins, 2555

41200-470 - Salvador - BA - Brasil. 